\title{
REFLEXÕES SOBRE A TRANSIÇÃO PARADIGMÁTICA EM SAÚDE MENTAL
}

Edna Paciência Vietta*

Sérgio Kodato**

Reinaldo Furlan**

Vietta EP, Kodato S, Furlan R. Reflexões sobre a transição paradigmática em saúde mental. Rev Latino-am Enfermagem 2001 março; 9(2): 97-103.

Este trabalho é o produto da reflexão dos autores frente à necessidade de mudanças conceituais, na área da saúde mental. Os autores buscam apreender aspectos essenciais que envolvem a temática à luz da concepção de paradigma, bem como o processo no qual a crise se precipita emergindo anomalias que apontam para a ineficiência do paradigma vigente. Os autores sugerem a substituição do modelo em vigor por um outro que se oriente para uma perspectiva que busque preservar a liberdade do paciente e o caráter relacional da expressividade humana.

UNITERMOS: saúde mental, assistência psiquiátrica

\section{REFLECTIONS ABOUT THE MENTAL HEALTH PARADIGMATIC TRANSITION}

This work is a result of authors' reflection on the necessity of conceptual changes in the area of mental health. The authors aimed at understanding the essential aspects involving the theme according to the conception of paradigm, as well as the process in which the crisis appears emerging anomalies and pointing out the inefficiency of the present paradigm. Thus, they suggested a change from the actual model to another one based on a perspective that emphasizes patient's freedom and the relational character of human expressiveness.

KEY WORDS: mental health, psychiatric care

\section{REFLEXIONES SOBRE LA TRANSICIÓN PARADIGMÁTICA EN LA SALUD MENTAL}

Este trabajo es el producto de la reflexión de los autores frente a la necesidad de mudanzas conceptuales en la área de salud mental. Los autores buscan aprehender aspectos esenciales de ésta temática a la luz del concepto de paradigma, así como también en el proceso en el cual la crisis se precipita, trayendo anomalías que muestran la ineficiencia del paradigma actual. Los autores sugieren la sustitución del modelo vigente por otro que se oriente hacia una perspectiva que logre preservar la libertad del paciente y el carácter relacional de la expresividad humana.

TÉRMINOS CLAVES: salud mental, asistencia psiquiátrica

\section{INTRODUÇÃO}

$\boldsymbol{O}_{\text {s fatores desencadeantes das sucessivas crises na área }}$

da saúde no Brasil são múltiplos e situam-se dentro e fora das ciências médicas, estando inextrincavelmente ligados à crise mais ampla, de natureza sócio-cultural, com especificidades de ordem política e econômica e na organização técnica e conceitual do sistema de atendimento como um todo.

\footnotetext{
* Professor Titular aposentada do Departamento de Enfermagem Psiquiátrica e Ciências Humanas da Escola de Enfermagem de Ribeirão Preto da Universidade de São Paulo, Centro Colaborador da Organização Mundial da Saúde para o desenvolvimento da pesquisa em Enfermagem. E-mail: vietta@netsite.com.br

** Professores Doutores do Departamento de Psicologia e Educação da faculdade de Filososfia, Ciências e Lestras de Ribeirão Preto da Universidade de São Paulo
} 
0 país vem atravessando um período de agravamento em suas condições sociais, afetando sobremaneira o cotidiano da população, sendo que, nesta conjuntura, o setor saúde piorou consideravelmente. Esta problemática atinge todas as camadas da sociedade, traduzindo-se em desconforto para os usuários do sistema, revoltas, aumento do número de óbitos por falta de assistência e aos profissionais da área, que se vêem impotentes diante da demanda que se avoluma.

É impossível separar a função saúde do inteiro arcabouço institucional, político e social da qual faz parte ${ }^{(1)}$. Qualquer sistema de assistência à saúde é produto de sua história e deve ser compreendido dentro do contexto sócio-cultural no qual se insere.

Um número crescente de estudiosos, envolvidos direta e indiretamente nas ciências médicas, reconhecem as deficiências do atual sistema e ainda apontam, como influências indiretas desta crise, a estrutura conceitual que serve de suporte à teoria e à prática destas ciências. É sobre este aspecto que pretendemos orientar a temática do presente estudo, focalizando especificamente a necessidade de adoção de novos paradigmas na saúde mental.

A mudança de paradigmas na assistência à saúde mental faz-se necessária e traz em seu bojo a convicção da necessidade de formulação de outros modelos conceituais, além da reformulação das próprias instituições, principalmente aquelas que lidam com o doente mental e implicam a implementação de uma nova política de saúde. Esta perspectiva deve oferecer alternativas de ação compatíveis com a realidade concreta das instituições e do país.

Nesse sentido, estabelecemos como objetivos do presente estudo: a) algumas reflexões sobre paradigmas na saúde mental, suas origens, evolução e indícios emergenciais que apontam para a adoção de nova estrutura conceitual; b) sugerir dentro de nossa cosmovisão uma orientação alternativa para a contribuição de um novo paradigma para a saúde mental.

\section{COMPREENDENDO O CONCEITO - PARADIGMA}

Mas o que vem a ser paradigma?

- É toda uma estrutura conceitual e operacional de que dispõe uma determinada comunidade científica no exercício de sua atividade $^{(2)}$. São os elementos básicos, fundamentais, compartilhados por membros de uma ciência ou por profissionais que no exercício de suas práticas adotam princípios comuns. Inversamente, diríamos que uma comunidade cientifica ou categoria profissional se constitui de um grupo de homens que partilham um mesmo paradigma. Estes profissionais/cientistas certamente são submetidos a uma formação profissional articulada ou educação similar, numa extensão sem precedentes com a maioria das outras disciplinas, o que lhes confere peculiaridade e identidade paradigmática. É claro que, de acordo com a sincronia dos fatos, um ou outro de seus membros pode se destacar no domínio mais específico de certa região de investigação, porém a maioria dos membros dessa comunidade absorveu a mesma literatura técnica e treinamento específico, delas incorporando 0 que é comum, o cerne epistemológico e instrumental.

Normalmente, as fronteiras dessa literatura padrão marcam os limites de um objeto de estudo científico e em geral cada comunidade ou profissão possui seu recorte temático singular, constituindo objeto de estudo próprio. No interior destes grupos, a comunicação é relativamente ampla e os julgamentos profissionais relativamente unânimes. Este consenso se efetua graças aos elementos constitutivos de um paradigma ou do conjunto deles, ou seja, de sua matriz disciplinar.

Dito de outro modo, os paradigmas estão diretamente ligados a determinadas visões de mundo da comunidade científica, e determinam ações e estratégias terapêuticas e de prevenção. Durante um período de tempo detectam problemas e sugerem soluções modelares para uma comunidade. Nessa concepção, um primeiro sentido sociológico do conceito de paradigma indica toda a constelação de crenças, valores, procedimentos e técnicas partilhadas no consenso de um certo grupo ou cultura.

Em outras palavras, paradigma refere-se a modelo, padrão e vivências compartilhadas, configurando-se num esquema exemplar de descrições e compreensão da realidade. É, portanto, mais que teoria, pois implica em uma estrutura que gera teorias, produzindo pensamentos e explicações, representando um sistema de aprender a aprender ao qual vincula todo processo futuro de aprendizagem e indica um método para a investigação.

0 paradigma entra em crise quando há fracasso na solução dos problemas por ele propostos, abalando a crença em suas próprias regras e padrões conceituais. 0 fracasso nas regras existentes é o prelúdio para a busca de novas alternativas ${ }^{(2)}$.

A emergência de uma nova estrutura conceitual é, pois, geralmente precedida por um período de stress e insegurança profissional gerada pelo fracasso constante e frustração de esforços para solucionar problemas. “...É como se o solo debaixo de nossos pés tivesse sido retirado sem que nenhum fundamento firme sobre o qual se pudesse construir estivesse à vista"(2)

\section{SAÚDE MENTAL E A NECESSIDADE DE NOVOS PARADIGMAS}

Na Psiquiatria, bem como em outras áreas correlatas, começaram a emergir indícios que constituem uma sensação geral de insatisfação com os modelos existentes, gerando crises, condições 
precárias de atendimento, dando início à demanda por novos esquemas. Durante muitos anos a psiquiatria lutou sem limites para ser admitida como especialidade médica ${ }^{(3)}$. Após esta conquista, a análise da prática do modelo médico* aponta para uma insuficiência. Se por um lado houve um avanço enorme, principalmente na tecnologia aplicada aos exames diagnósticos, como a tomografia computadorizada e cirurgias a laser, por outro, este modelo revelouse obscuro e ambíguo na abordagem dos problemas emocionais e de conduta, não consolidando sua teoria, nem apresentando significativas soluções. "0 modelo dominante é fornecido pela racionalidade anatomopatológica, estando a racionalidade psicológica sobre as inter-relações num plano marcadamente secundário, e mesmo ausente" ${ }^{\prime(4)}$. Com isso a doença mental na população continuou à margem de qualquer processo de equacionamento diagnóstico, das possibilidades de "cura" ou de respostas atenuantes para o seu desconforto e sofrimento. Diante da impotência oficial, diante do caos dos serviços de saúde mental, o que mais se disseminou no campo do diagnóstico das doenças mentais foi o termo "mal crônico", sintomaticamente. "...A ética da psiquiatria termina onde começa a pobreza e 0 asilo. A gente tem de dizer isto, em alto e bom som. Calar é cumplicidade" ${ }^{(5)}$.

Embora atualmente, o paradigma que predomina na área da saúde mental é ainda o do modelo médico, as referências e conceitos que permeiam a assistência psiquiátrica está emitindo sinais de esgotamento, pois todo progresso teórico e tecnológico tem se revertido num paradoxo, de cirurgias e medicamentos altamente sofisticados e de altíssimo custo, à assistência precária e insuficiente para a grande maioria da população, consubstanciada por uma prática repressiva, cronificadora e estigmatizante, que não atende às necessidades do doente.

0 baixo índice de resolutividade, o encarceramento improdutivo dos esquizofrênicos crônicos, a reprodução das doenças mentais, a pressão da demanda em nível da população, todos esses fatores reforçam e confirmam a necessidade da emergência de novos paradigmas, com novos modelos de assistência.

Outro fator implicado na transição paradigmática é a mitificação da ciência, como se ela pudesse resolver todos os problemas do homem. 0 que tem-se observado na área da saúde mental é que em certo sentido houve um efeito contrário, onde 0 conhecimento "científico" parece ter contribuído para piorar o nível de saúde da população, pois com sua pretensão ao monopólio do saber e da técnica, expropriou amplas camadas de seu conhecimento advindo do senso comum sobre seu corpo e a doença, canalizando tudo para a ordem médica, não oferecendo em contrapartida assistência adequada à maioria dos indivíduos desassistidos e desprovidos de seus recursos culturais.

Não se pode ignorar que a objetividade da ciência nos auxilia a chegar a uma compreensão útil de certos fenômenos, porém, imaginar que todos os aspectos da vida humana, principalmente os relacionados ao funcionamento da "mente", possam ser reduzidos a princípios mecanicistas tipo causa-efeito é incorrer num forte reducionismo.

\section{EVOLUÇÃO E TENDÊNCIA PARADIGMÁTICA DO CONCEITO DE SAÚDE MENTAL}

A evolução dos conceitos "saúde" e "doença", as representações da doença mental, as estratégias de cura estão portanto relacionadas aos paradigmas adotados ao longo dos tempos e tem suas origens nos primórdios das civilizações.

0 paradigma mais antigo sobre o conceito de saúde e doença, tem origem no pensamento pré-lógico e mágico do homem primitivo. Nesta perspectiva, explica-se a doença da mesma e única maneira que se explica tudo o que existe no mundo, de forma sobrenatural. Portanto, as primeiras tentativas do homem no controle das doenças surgem através de explicações mágico-religiosas, com as causas sendo atribuídas a outros seres humanos ou fenômenos sobrenaturais, numa atitude animista.

Até a idade média, o modelo predominante da psicopatologia era, portanto, o da concepção místico-religiosa, segundo a qual o comportamento desviante era considerado através das noções de demoníaco, de feitiçaria, de despossessão. Este modelo vigorou até a renascença e o começo do humanismo.

As psicologias filosóficas do século XVII forneceram aos médicos um conhecimento menos fatalista do ser enfermo, fazendo declinar o poder da teologia. A partir daí, dogmas religiosos foram se transformando gradativamente em dogmas da razão. Mas é somente no Renascimento e com a Reforma que os loucos deixam de ser considerados possuídos pelo demônio, e passam a ser encarados como pessoas perigosas ou improdutivas, tais como os criminosos, os miseráveis que subsistem graças à mendicância; por esta razão serão excluídos da sociedade e internados com outras categorias de doentes, por vezes nos mesmos lugares, como por exemplo, nos leprosários.

Ocorreu profunda transformação em meados do século $\mathrm{XVII}$, em relação à tolerância da sociedade à loucura ${ }^{(6)}$ : o mundo da loucura se transforma no mundo da exclusão: "antes do século

\footnotetext{
* Modelo Médico: a essência do Modelo Médico consiste em definir a entidade patológica (doença), depois isolar os organismos invasores (germes, vírus, bactérias etc) e desenvolver ou descobrir a droga ou vacina específica que destruirá esses organismos (cura)
} 
XVIII, a loucura não era sistematicamente internada, e era essencialmente considerada como uma forma de erro ou de ilusão"(7).

A partir do século XVIII deu-se "o grande confinamento", $a$ institucionalização da loucura ${ }^{(6)}$. Os novos valores, ligados à mentalidade da era moderna, são fundamentados no trabalho e no dinheiro. Consolidam-se as idéias capitalistas e com estas o conceito de lucro e a idéia de que só o trabalho produz riquezas. Os loucos agora não são mais "possuídos", mas "improdutivos" e "vagabundos", portanto, uma ameaça social e um problema moral. A responsabilidade sobre a loucura deixa de ser da coletividade caridosa e passa às mãos dos médicos.

E em meio a descobertas significativas no campo da biologia, física, e química, a medicina postula que a loucura tem causas físicas, e procura no substrato orgânico as suas origens. 0 que levará a psicopatologia do século XVIII a um impasse pois "a neurofisiologia do período não tinha condições para determinar e localizar substratos orgânicos claros para a loucura e, muito menos, correlatos cerebrais específicos para as diversas formas de insanidade. Mas a postura médica de recusar qualquer 'filosofia' ou uma visão 'passional' da loucura impõe a procura das mudanças orgânicas subjacentes ao delírio e ao comportamento desviante" ${ }^{(8)}$. Nesse contexto, no final do século XVIII, surge Pinel, seguido depois por Esquirol, e emerge uma teoria moral sobre a loucura ${ }^{(8)}$.

Pinel e Esquirol comumente são lembrados como responsáveis pelo desacorrentamento dos loucos e pelas reformas nos manicômios, que se espalharam pela Europa no início do século XIX. Mas sob a promoção da humanização no tratamento dos loucos, havia determinada concepção de loucura que representava a originalidade propriamente do pensamento de Pinel. Baseado nas teorias de Locke e Condillac, Pinel concebe a loucura como doença moral: não é no órgão que se localiza a origem da maior parte das doenças mentais, mas no desarranjo das impressões sensíveis responsáveis pela produção de idéias e vínculo com a realidade, o que por si acarreta a ocorrência de comportamentos imorais. Por isso a loucura é basicamente um erro, e o papel do médico é reconduzir o doente à racionalidade. Como o desarranjo perceptivo é causado por fortes paixões vividas pelo sujeito, o ambiente do tratamento e as atividades terapêuticas deveriam ser adequados ao restabelecimento da racionalidade. Daí a importância de um ambiente calmo e tranqüilo, da ausência de situações conflituosas e ameaçadoras - o que justificava o isolamento do louco nos manicômios, longe dos conflitos familiares e sociais - de disciplina para coibir a desordem na relação com o mundo, de passeios e música para restaurar o contato com a realidade, etc. Algumas dessas atividades também seriam prescritas pelos organicistas, mas com outra concepção de doença, porque estes acreditavam que algumas dessas atividades atuariam sobre os órgãos afetados, e por isso prescreviam, sob o mesmo princípio, tratamentos físicos de excessiva violência para o paciente, recusados pelos moralistas justamente por provocarem mais paixões violentas nos pacientes. É importante frisar, a importância afetiva da presença do médico no tratamento do louco, já que se tratava de uma ligação a uma só vez terapêutica e pedagógica na reordenação das idéias delirantes e do comportamento imoral ${ }^{(8)}$.

Mas as teorias morais da doença foram paulatinamente cedendo lugar à noção de lesões anatomopatológicas, e a loucura no final do século XIX encontra-se inserida totalmente no discurso médico organicista. Consolidava-se a idéia da possibilidade do comportamento humano irracional vir a ser explicado pelo funcionamento anormal de cérebro, a par com descobertas no campo da microbiologia e neurologia no final do século.

Durante o século XX, os psiquiatras vão buscar as explicações nas desordens do comportamento, da afetividade e do pensamento em causas físicas como as lesões ou modificações da matéria cerebral. Esta orientação organicista resultou da transferência de conceitos e métodos considerados úteis no tratamento das doenças físicas para o campo dos distúrbios emocionais e comportamentais.

Embora essa abordagem tenha fracassado para 0 esclarecimento e etiologia da maioria dos distúrbios mentais, foi amplamente adotada. Acreditando que os distúrbios mentais se baseavam em mecanismos biológicos específicos, deu-se grande ênfase ao estabelecimento do diagnóstico correto, para o qual utilizou-se um sistema reducionista de classificação.

No século XX, a despeito da descoberta da origem sifilítica da paralisia progressiva e dos contínuos esforços na busca de um bacilo causador da esquizofrenia, o modelo médico psiquiátrico entra em decadência, dado o insucesso nos resultados e ineficácia dos tratamentos utilizados.

Surgem inquietações ao mesmo tempo em que se agrava a situação dos asilos, com denúncias de maus tratos aos pacientes e de superlotação dessas instituições. Neste período de ascensão e declínio da psiquiatria surge uma luz no fim do túnel e perspectivas de melhoria da qualidade da assistência psiquiátrica com as descobertas de Freud. A partir da "interpretação dos sonhos", este autor descortinava um novo, desconhecido e complexo terreno humano, o inconsciente. “...As paralisias histéricas não reenviavam ao corpo concreto da medicina, corpo anatomopatológico, mas a um corpo representado pelo enfermo, corpo simbólico. Assim, as linhas corporais fixadas pela operação conversiva se orientavam pela geografia corporal estabelecida no imaginário destes pacientes" ${ }^{(4)}$.

Enquanto Kraepelin, numa perspectiva semiológica 
médico-neurológica procurou por trás dos sintomas psiquiátricos apenas entidades mórbidas, Freud, ao contrário, descobre que os sintomas têm sentido e são menos os indícios de uma doença, do que a mensagem a ser interpretada de um indivíduo que não pode expressar-se senão por eles. É a via e a forma pela qual se processa a descarga pulsional que é absolutamente inusual, podendo até mesmo manifestar- se pelo seu oposto. É o homossexualismo recalcado que assume a forma de um delírio de ciúmes, é o desejo inconsciente que reprimido retorna na forma de uma paralisia histérica, é o próprio sonho, realização deslocada e condensada do desejo.

Do outro lado, na década de 50, surgem os psicofármacos que, se por um lado promovem substancial modificação na atmosfera dos hospitais psiquiátricos, favorecendo de certa forma o progresso da psicoterapia individual e grupal, os hospitais-dia, os hospitaisnoite, e outras modalidades socioterápicas, por outro criaram um problema, qual seja, como reduzir ou anular os efeitos colaterais, as manifestações delirantes por eles provocadas e as expressões motoras que acompanham estes medicamentos**.

A partir do conhecimento sobre as relações das doenças mentais com os fatores ambientais e sociais, descobriu-se a necessidade de não apenas lidar com as raízes biológicas dos problemas mentais, mas também com os fatores sociais. Surge a psiquiatria social. Esta passa a descrever as estruturas sociais como fatores geradores de doença, estando nesse ponto os alicerces do movimento de saúde mental e da antipsiquiatria.

Verificou-se a partir daí, um crescente interesse no objetivo preventivo de se promover saúde mental em contraposição ao objetivo puramente atenuante de se amenizar a gravidade da doença mental, ao menos como proposta.

O hospital psiquiátrico do século XX é convocado a repensar suas reais funções. De mero oferente de isolamento e proteção estéril ao doente mental, passa a ter que proporcionar situações terapêuticas, condizentes com seus autênticos propósitos.

No entanto, os hospitais não conseguiram concretizar este intento dado suas características inerentes a esse contexto: número reduzido de recursos humanos; inexistência de estratégias terapêuticas; despreparo do pessoal disponível; desinteresse por parte dos administradores e superlotação, além das características de instituição total. 0 ambiente hospitalar psiquiátrico, sobretudo os grandes hospitais estatais foram considerados, portanto ambientes propícios à proliferação e cronicidade iatrogênica do internado, levando-o ao institucionalismo***, à neurose institucional $^{* * * *}$ e à contaminação ou deterioração do eu****.

Em relação a esses fatores prejudiciais, a maioria dos pacientes começa a apresentar dois tipos de doença: a esquizofrenia e a neurose institucional ou hospitalismo ${ }^{(11)}$. 0 asilo de loucos provou seu caráter antiterapêutico e iatrogênico, não tendo sido só uma técnica ou instrumento que se revelou ineficaz em seu interior, mas desvelando todo o conjunto da organização hospitalar, em sua capacidade técnica $^{(12)}$.

Em 1960 surge com todo vigor no bojo do movimento de saúde mental a estratégia psicoprofilática, abrangendo, nas atuações comunitárias, ações em níveis de prevenção primária, secundária e terciária. Esse modelo foi severamente criticado como sendo provocador da invasão de um número cada vez maior de setores da vida pessoal, como passíveis de serem medicados e tratados por especialistas e técnicos da área. A medicalização da psiquiatria já era termo consagrado, sob a denominação de psiquiatrização, e a oposição a essa perspectiva, uma das bandeiras do movimento da antipsiquiatria ${ }^{(12)}$. Afirmava este autor que a partir do fenômeno da psiquiatrização, a ideologia dominante do sistema de saúde se voltava para a normatização e controle do comportamento social em países capitalistas, induzindo as populações à crença na possibilidade ilimitada da ciência médica e na solução técnica de todos os problemas da vida. Com isto, desencadeia-se na década de 70 um aumento da demanda aos serviços de saúde mental a ponto de se questionar: aumentaram as perturbações mentais ou promoveu-se a psiquiatrização? A oferta dos serviços gera a demanda?

Assim, o final do século XX aponta para a proposta de reformulação assistencial e da cultura manicomial, tendo como temas centrais: a instituição asilar, a cidadania do "louco" e os modelos assistenciais. Na década de 70 inicia-se o movimento da psiquiatria democrática inspirada no sistema instalado na Itália por Franco Basaglia, que apontou para o fim dos manicômios, começando a se

\footnotetext{
** 0 entusiasmo pela redução do tempo de internação, graças ao controle dos sintomas sufocados por neurolépticos, revelou-se ilusório, tanto que 0 número de internações após sua utilização não foi menor. Na verdade, constatou-se que o tratamento por meio de substância química "controla os sintomas, mas não os cura ${ }^{(9)}$

*** Instutucionalismo é um fenômeno patogênico identificado e definido como uma síndrome que se desenvolve no ambiente institucional e que limita a capacidade do indivíduo para viver fora do hospital. Não se trata de institucionalizar, da adaptação do paciente às regras e normas de vida dentro do hospital, mas da amputação psicológica e funcional que a vida do hospital causa ao indivíduo ${ }^{(10)}$

**** Neurose institucional é a perda de interesse especialmente pelos assuntos de natureza impessoal, submissão, visível inabilidade para fazer planos para o futuro, falta de individualidade e algumas vezes posturas e marcha características ${ }^{(11)}$

***** A contaminação ou deterioração do Eu acontece em consequência das várias e constantes agressões que 0 indivíduo sofre, sem condições de defesa, em instituições fechadas e superlotadas ${ }^{(9)}$
} 
articular o paradigma da desinstitucionalização em saúde mental.

Surge no Brasil a proposta de reformulação da assistência manicomial do século XX e com ela o projeto de Lei 08/91-c, do deputado Paulo Delgado, que prescreve a extinção progressiva dos hospitais psiquiátricos brasileiros e adoção de recursos terapêuticos alternativos para atender os doentes mentais. Este movimento busca combater as políticas hospitalocêntricas, opressivas e estigmatizantes que negam a cidadania ao doente mental.

A desinstitucionalização do doente mental traz no seu bojo o desafio de dotar esse indivíduo de um mínimo de recursos vitais que the permita independência para as atividades de vida diária e exercício de cidadania. Imaginar o crônico, há anos institucionalizado, lentamente saindo do cotidiano do asilo, frequentando as oficinas ocupacionais, os hospitais-dia, as vilas-terapêuticas, as pensõesprotegidas, as repúblicas, enfim resgatando sua livre gestão e seu direito de ir e vir, é algo que além de muita imaginação requer obstinação e criatividade terapêutica.

\section{CONTRIBUIÇÃO À REFLEXÃO RUMO A UM NOVO PARADIGMA}

Avolumam-se as demandas pela emergência de novas formas de atendimento em saúde mental, a necessidade de adoção de estratégias de desinstitucionalização e novos dispositivos grupais e institucionais, como as oficinas terapêuticas, que busquem resgatar a saúde mental em sua cidadania, ativa e produtiva. 0 paradigma da desinstitucionalização aponta para a necessidade da desconstrução de todo um sistema de saber erigido em função do hospital psiquiátrico, da transformação das relações de poder entre a equipe técnica e a clientela e a interdisciplinariedade, enquanto articulação efetiva das áreas de saber envolvidas de modo a constituir o novo campo da saúde mental ${ }^{(13)}$.

Um novo paradigma implica, pois, um outro olhar sobre a loucura, uma outra atitude de cidadania e uma distinta estratégia terapêutica. Nesse sentido evoca-se a figura de Silveira ${ }^{(14)}$, seu atelier terapêutico, seu museu de imagens do inconsciente, seus gatos coterapeutas, seu método convicto no imaginário enquanto fonte de produção terapêutica. Como dizia a autora ${ }^{(14)}$ “...a criatividade é 0 catalisador por excelência da aproximação de opostos. Por seu intermédio, sensações, emoções, pensamentos são levados a reconhecer-se, a associar-se".

Encerramos, assim, com a alusão a duas formas de pensamento que apontam para a necessidade de revisão dos pressupostos metafísicos de nossas teorias, na qual incluímos, naturalmente, a própria Psiquiatria. Com isso sinalizamos, também, a direção que parecer tomar a transição paradigmática em saúde mental.

A crise da Psiquiatria é antes de tudo uma crise de poder ${ }^{(6)}$. No caso, resta saber se a loucura ou o louco podem ser tratados segundo a objetividade das ciências naturais, isto é, se a relação médico-loucura (ou médico-paciente) pode se dar nos quadros da relação sujeito-objeto que organiza todo o nosso conhecimento científico. Uma visão estritamente organicista da loucura não questiona, naturalmente, a relação sujeito-objeto de conhecimento. Por isso Foucault fala que a psico-cirurgia e a psiquiatria farmacológica modernas podem visar à redução do poder do médico aos sintomas mínimos da doença, ao contrário de sua produção ou exacerbação - como nos tratamentos de Charcot -, mas não contestam esse poder que lhes é conferido pelo "conhecimento objetivo". A psicanálise, porque entende que os sintomas expressam o sentido da doença, procura, ao contrário, intensificá-los, mas numa relação eqüitativa médico-paciente. Ao médico cabe apenas escutar e servir de apoio para a transferência dos conflitos inconscientes do paciente, que devem tornar-se conscientes nessa relação, de modo que o sujeito possa assumir o destino de sua vida. É claro que para para Foucault o espaço da escuta psicanalítica ainda é um espaço de poder, inserido no dispositivo histórico da sexualidade, mas de qualquer forma, a psicanálise contrapõe-se à psiquiatria clássica porque entende que o paciente deve assumir os conflitos expressos em seus sintomas, ao invés de simplesmente eliminá-los através de fármacos e intervenções cirúrgicas. Por fim, Foucault vislumbra no movimento da antipsiquiatria a contestação do par sujeito-objeto no conhecimento da loucura. Resta saber, pergunta ele, se a loucura pode ser tratada não em nome de um saber, mas no reconhecimento da alteridade do louco ou de sua experiência. Podemos interagir com ela, e vice-versa, e nessa troca encontra-se a possibilidade de auxílio, assumida pela individualidade de cada um.

Mas é com a psiquiatria existencial, fundada na analítica heideggeriana do Dasein que explicitamente rompe com as categorias da metafísica clássica, que encontramos o que nos parece ser a direção fundamental da transição paradigmática no tratamento da loucura ou das desordens mentais ${ }^{(15)}$. A analítica revela o homem como ser no mundo, isto é, como um saber-se sendo em relação com o mundo e o outro em direção à própria morte. A loucura, nesse sentido, só pode ser entendida a uma só vez como um desarranjo da existência do homem e uma forma característica de existir: ela tem sempre um sentido porque representa uma forma de projeção do homem no mundo. Talvez tenha sido Merleau-Ponty, no bojo do movimento estabelecido pela filosofia heideggeriana, quem melhor expressou a necessidade de uma reforma das categorias da metafísica clássica para a compreensão das relações entre o somático e o psíquico. Concebendo a existência como 
projeção do corpo na relação de sentido com o mundo (recusando, portanto, a concepção mecanicista de corpo), torna a existência acessível à doença tanto a partir dos sentidos vividos, quanto a partir do desarranjo do próprio corpo nessa relação ${ }^{(16,17)}$. Neste caso, a estrutura da relação corpo-mundo pode se alterar em decorrência da lesão do próprio corpo, que deve, então, refazer sua relação com o mundo a partir da organização dos elementos de que dispõe. Não se fecha, assim, as portas para uma

\section{REFERÊNCIAS BIBLIOGRÁFICAS}

1. Dantas VA. Enfermagem e os serviços básicos. Anais do $33^{\circ}$ Congresso Brasileiro de Enfermagem 1981;. Manaus; AM. Brasília: ABEn; 1981.

2. Kuhn TS. The structure of scientific revolution. Chicago: University of Chicago Press; 1962.

3. Torrey EF. A morte da psiquiatria. Rio de Janeiro: Paz e Terra; 1976.

4. Birman J. Enfermidade e loucura. Rio de Janeiro: Campus; 1980.

5. Costa JF. História da psiquiatria no Brasil. $4^{\mathrm{a}}$ ed. Rio de Janeiro: Xenon; 1989.

6. Foucault M. Microfísica do poder. Rio de Janeiro: Graal; 1979.

7. Foucault M. A história da loucura na época clássica. São Paulo: Graal; 1981. compreensão futura das "bases orgânicas" da doença, embora estas devam ser vistas sempre na relação do organismo com o meio. 0 que se enfatiza é que mesmo na loucura estamos diante da existência de um outro. Também não se fecha a possibilidade do conhecimento, afinal, "a psicologia, a etnologia, a sociologia, só nos ensinaram alguma coisa colocando a experiência mórbida ou arcaica, ou simplesmente outra, ao contato de nossa experiência, esclarecendo uma pela outra, criticando uma pela outra" ${ }^{\text {(16) }}$.

8. Pessotti I. 0 século dos manicômios. São Paulo: Editora 34; 1996. 9. Tehns K. Etologia. São Paulo: Círculo do Livro; 1977.

10. Negrete JC. La epilepsia como problema de salud publica. São Paulo: Coordenadoria de Saúde Mental do Estado de São Paulo; 1974.

11. Barton R. Institutional neurosis. New York: John Wright; 1959.

12. Szasz ST. Ideologia e doença mental: ensaios sobre a desumanização do homem. Rio de Janeiro: Zahar; 1977.

13. Vasconcelos E. Do hospício à comunidade. Belo Horizonte: SEGRAC; 1992.

14. Silveira N. 0 mundo das imagens. São Paulo: Ática; 1992.

15. Heidegger M. Ser e Tempo. $3^{a}$ ed. Petrópolis: Vozes; 1989.

16. Merleau-Ponty M. Le Visible et l'invisible. Paris: Gallimard; 1964. 17. Merleau-Ponty M. Fenomenologia da Percepção. São Paulo: Martins Fontes; 1994. 